\title{
IMPLEMENTASI TWITTER SENTIMENT ANALYSIS UNTUK REVIEW FILM MENGGUNAKAN ALGORITMA SUPPORT VECTOR MACHINE
}

\author{
Faisal Rahutomo ${ }^{1}$, Pramana Yoga Saputra ${ }^{2}$, Miftahul Agtamas Fidyawan ${ }^{3}$ \\ ${ }^{1,2}$ Program Studi Teknik Informatika, Jurusan Teknologi Informasi, ${ }^{3}$ Politeknik Negeri Malang \\ ${ }^{1}$ faisal@polinema.ac.id, ${ }^{2}$ pramanay@gmail.com, ${ }^{3}$ agtamasmiftahul37@gmail.com
}

\begin{abstract}
Abstrak
Sentiment analysis digunakan untuk melihat opini terhadap sebuah masalah menuju ke opini positif atau negatif. Media sosial Twitter merupakan salah satu media yang digunakan untuk memberikan opini melalui tweet. Pengguna Twitter akan memberikan opini tentang suatu hal, salah satunya film yang sedang tayang di bioskop. Opini pengguna bermanfaat bagi pengguna lain dan rumah produksi film berkaitan evaluasi film. Klasifikasi opini diperlukan untuk memudahkan pengguna dalam melihat opini positif, negatif, atau netral. Algoritma yang digunakan dalam klasifikasi adalah Support Vector Machine. Dataset berjumlah 1.027 tweet yang didapatkan dari tweet untuk film populer tahun 2016. Hasil klasifikasi opini terbagi menjadi 3, yaitu opini positif, negatif, dan netral. Evaluasi menentukan tingkat akurasi dari algoritma Support Vector Machine. Hasil akurasi klasifikasi algoritma Support Vector Machine menggunakan 60, 70, 80, dan 90 persen data training rata- ratanya adalah 76,06 persen, 76,83 persen, 81,07 persen, dan 83,3 persen. Nilai precision positif memiliki rata- rata sebesar 79,97 persen, 78,71 persen, 84,02 persen, dan 85,54 persen. Nilai precision negatif memiliki rata- rata sebesar 81,73 persen, 87,41 persen, 87,37 persen, dan 93,61 persen. Nilai precision netral memiliki rata- rata sebesar 67,13 persen, 69,47 persen, 74,08 persen, dan 74,14 persen.
\end{abstract}

Kata kunci : Twitter Sentiment Analysis, review film, Support Vector Machine

\section{Pendahuluan}

Media sosial Twitter adalah salah satu media komunikasi yang diminati oleh masyarakat di dunia. Hal ini dapat dilihat dari peningkatan pengguna Twitter yang tercatat di seluruh dunia. Twitter memiliki jumlah pengguna aktif sebesar 313 juta per bulan pada tahun 2016. Pengguna akan memberikan kabar terbaru atau komentar tentang hal yang sedang menjadi topik utama di dunia. Hal yang sedang menjadi topik utama dan banyak dikomentari oleh pengguna akan menimbulkan trending topic di Twitter.

Pengguna Twitter yang semakin meningkat akan menimbulkan peningkatan tweet yang diposting. Tweet tersebut dapat memuat opini dan komentar publik yang berkaitan dengan bidang ekonomi, perilaku sosial, fenomena alam, perdagangan, pendidikan, hiburan, dan lain- lain. Hal yang berkaitan dengan hiburan antara lain film yang sedang ditayangkan di bioskop [1]. Pengguna akan memberikan komentar dan opini tentang film yang sedang populer melalui Twitter. Pengguna akan memberikan penilaian terkait dengan film yang telah dilihat. Informasi berupa tweet dari pengguna akan menjadi referensi bagi pengguna Twitter yang lain apabila ingin melihat film yang sama. Tweet dari pengguna juga dapat menjadi evaluasi bagi rumah produksi film terkait dengan film yang telah diproduksi. Tweet yang masih tersusun secara acak menyebabkan kesulitan bagi pengguna dalam mengetahui opini positif, negatif, atau netral.

Berdasarkan penjelasan yang telah dipaparkan, akan dilakukan penelitian tentang Twitter sentiment analysis untuk mengklasifikasikan tweet review film berbahasa Indonesia. Data tersebut akan diproses menggunakan text mining, kemudian dilanjutkan dengan mengklasifikasikan tweet ke dalam tiga kelas, yaitu positif, negatif, dan netral. Klasifikasi ini menggunakan algoritma Support Vector Machine. Klasifikasi dapat memberikan kemudahan bagi pengguna untuk melihat opini positif, negatif, dan netral. Tingkat akurasi dari algoritma akan memberikan pengaruh pada hasil klasifikasi.

\section{Tinjauan Pustaka}

\subsection{Penelitian yangTerkait}

Twitter merupakan salah satu media sosial yang populer digunakan oleh pengguna saat ini [2]. Hal ini menyebabkan beberapa penelitian dilakukan dengan memanfaatkan Twitter sebagai media yang digunakan. Penelitian yang pernah dilakukan sebelumnya terkait dengan Twitter Sentiment Analysis dilakukan oleh Akshay Amonik, Niketan Jivane, Mahavir Bhandari, Dr. M. Venkatesan pada tahun 2015 Akshay (2016). 
Penelitian ini memanfaatkan Twitter Sentiment Analysis untuk klasifikasi review film menggunakan algortima Machine Learning. Penelitian ini membandingkan penggunaan dua algoritma dalam Twitter Sentiment Analysis, yaitu Naive Bayes Classifier dan Support Vector Machine. Dataset yang digunakan berjumlah 21.000 tweet berbahasa Inggris dan proses training menggunakan 1.800 tweet yang dibagi menjadi 600 tweet positif, 600 tweet negatif, dan 600 tweet netral. Dataset untuk testing berjumlah 150 tweet yang dibagi menjadi 50 tweet positif, 50 tweet negatif, dan 50 tweet netral. Kesimpulan yang didapatkan dari penelitian ini adalah penggunaan algoritma machine learning lebih mudah dan efisien dibandingkan algoritma symbolic. Tingkat akurasi algoritma Support Vector Machine menghasilkan 75 persen dan Naive Bayes Classifier menghasilkan 65 persen.

Penelitian terkait Twitter Sentiment Analysis yang lain, yaitu penelitian yang telah dilakukan oleh Sanket Sahu, Suraj Kumar Rout, Debasmit Mohanty pada tahun 2015 Sahu (2015). Penelitian ini menggunakan agoritma Support Vector Machine dan Maximum Entropy. Penelitian ini fokus pada tahap training dataset yang menggunakan tiga model, yaitu Opinion Lexicon, Labeled Sentimental Tweets, dan kombinasi dari kedua model. Dataset yang digunakan dalam proses training berjumlah 30.000 tweet positif dan 30.000 tweet negatif. Dataset untuk proses testing berjumlah 1.000 tweet. Word list yang digunakan, yaitu 2.000 kata positif dan 4.000 kata negatif yang akan digunakan untuk Opinion Lexicon sebagai dasar klasifikasi. Hasil yang didapatkan tingkat akurasi 69 persen pada unprocessed tweet, 73 persen pada processed tweet, dan 74, 2 persen pada kombinasi model.

Pada tahun 2015, Omar Abdelwahab, Mohamed Bahgat, Christoper J. Lowrance, Adel Elmaghraby melakukan penelitian Twitter Sentiment Analysis dengan fokus pada efek jumlah dataset pada proses training untuk algoritma Support Vector Machine dan Naive Bayes Classifier Abdelwahab (2015). Dataset yang digunakan untuk proses training berjumlah 4.269 tweet dan 782 tweet untuk proses testing. Training dilakukan 10 kali dengan urutan pada proses training pertama menggunakan 10 persen dataset training, proses kedua menggunakan 20 persen dataset training, hingga pada training ke10 menggunakan 100 persen dataset training. Hasil dari penelitian ini menunjukkan bahwa jumlah dataset akan memengaruhi tingkat akurasi dari algoritma Support Vector Machine dan Naive Bayes Classifier. Algoritma Support Vector Machine memiliki tingkat akurasi yang stabil antara 73 hingga 76 persen pada seluruh proses training. Algoritma Naive Bayes Classifier memiliki tingkat akurasi 67 persen pada pertama kali proses training, kemudian tingkat akurasi menjadi stabil antara 73 hingga 75 persen pada proses training selanjutnya.

\subsection{Text Mining}

Text mining adalah proses ekstraksi informasi dari data sumber yang belum terstruktur. Data yang belum terstruktur akan diolah menggunakan teknik dan metode tertentu menghasilkan informasi yang berguna untuk pengguna. Text mining merupakan teknik yang digunakan untuk menangani masalah classification, clustering, information extraction, dan information retrival Feldman (2007).

\subsection{Sentiment Analysis}

Sentiment analysis adalah proses memahami, mengekstrak, dan mengolah data tekstual secara otomatis untuk mendapatkan informasi sentiment yang terkandung dalam suatu kalimat opini. Sentiment analysis digunakan untuk melihat pendapat atau kecenderungan opini terhadap sebuah masalah atau objek oleh seseorang menuju ke opini positif atau negatif Berry (2010).

\subsection{Support Vector Machine (SVM)}

Support Vector Machine pertama kali diperkenalkan oleh Vapnik pada tahun 1992 sebagai rangkaian harmonis konsep- konsep unggulan dalam bidang pattern recognition Feldman (2007). SVM adalah algoritma machine learning yang bekerja atas prinsip Structural Risk Minimization (SRM) dengan tujuan menemukan hyperplane terbaik yang memisahkan dua buah class pada input space.

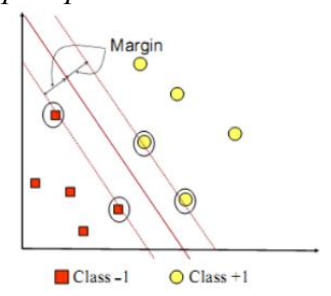

Gambar 1. Hyperplane Terbaik Yang Memisahkan Kedua Kelas -1 Dan +1

a. Kernel trick dan non linear SVM

Untuk menyelesaikan problem non linear, SVM dimodifikasi dengan memasukkan fungsi Kernel. Dalam non linear SVM, pertama- tama data $\mathrm{x}$ dipetakan oleh fungsi $\Phi(\mathrm{x})$ ke ruang vektor yang berdimensi lebih tinggi. Pada ruang vektor yang baru ini, hyperplane yang memisahkan kedua class tersebut dapat dikonstruksikan. 


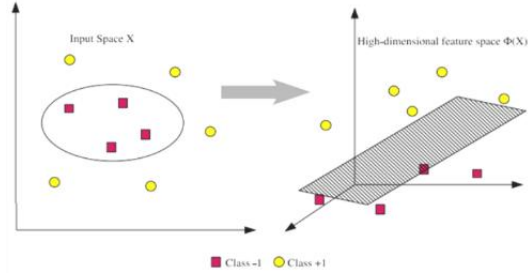

Gambar 2. Pemetaan Input Space Berdimensi Dua Dengan Pemetaan Ke Dimensi Tinggi

Proses pembelajaran pada SVM dalam menemukan titik- titik support vector, hanya bergantung pada dot product dari data yang sudah ditransformasikan pada ruang baru yang berdimensi lebih tinggi, yaitu :

$$
\Phi\left(x_{i}\right) . \Phi\left(x_{j}\right)
$$

Karena umumnya transformasi $\Phi$ ini tidak diketahui, dan sangat sulit untuk dipahami secara mudah, maka perhitungan dot product tersebut sesuai teori Mercer dapat digantikan dengan fungsi kernel yang mendefinisikan secara implisit transformasi $\Phi$. Hal ini disebut sebagai Kernel Trick, yang dirumuskan:

$$
K\left(x_{i}, x_{j}\right)=\Phi\left(x_{i}\right) . \Phi\left(x_{j}\right)
$$

Berbagai jenis fungsi kernel dikenal, sebagaimana dirangkumkan pada tabel.

Tabel 1. Kernel yang Umum Digunakan

\begin{tabular}{|c|c|}
\hline Jenis Kernel & \multicolumn{1}{|c|}{ Definisi } \\
\hline Polynomial & $K\left(x_{i}, x_{j}\right)=\left(x_{i}, x_{j}\right.$ \\
\hline $\begin{array}{c}\text { Gaussian } \\
\text { RBF }\end{array}$ & $K\left(x_{i}, x_{j}\right)=\exp \left(-\frac{\left\|x_{i}-x_{j}\right\|^{2}}{2 \sigma^{2}}\right)$ \\
\hline Sigmoid & $K\left(x_{i}, x_{j}\right)=\tanh \left(\alpha x_{i}, x_{j}\right.$ \\
& $K\left(x_{i}, x_{j}\right)=x_{i}{ }^{t} x_{j}$ \\
\hline Linear & \\
\hline
\end{tabular}

Selanjutnya hasil klasifikasi dari data xr diperoleh dari persamaan berikut.

$$
\begin{aligned}
& f(\Phi(x))=w . \Phi(x)+b \\
& =\sum_{i=1 . x, \in S V}^{n} \alpha_{i} y_{i} \Phi(x) . \Phi(x)+b \\
& =\sum_{i=1 . x, \in S V}^{n} \alpha_{i} y_{i} K\left(x, x_{i}\right)+b
\end{aligned}
$$

\section{b. Gaussian Kernel}

Gaussian Kernel adalah pilihan kernel yang menjanjikan. Kernel ini secara non linear memetakan sampel ke dalam ruang dimensi yang lebih tinggi, sehingga tidak seperti kernel linear, kernel ini dapat menangani kasus ketika hubungan antara label kelas dan atributnya tidak linear. Alasan kedua adalah pada kernel Gaussian Kernel,kompleksitas hyperparameter- nya lebih sedikit dibandingkan dengan kernel non linear lain seperti kernel polinomial dengan persamaan:

$$
K\left(x_{i}, x_{j}\right)=\exp \left(-\gamma\left\|x-x^{\prime}\right\|^{2}\right)
$$

\subsection{Twitter API}

Twitter API merupakan salah satu layanan yang disediakan oleh Twitter untuk pengembang. Twitter API dapat digunakan untuk mengembangkan aplikasi yang membutuhkan data dari Twitter. Fitur yang disediakan oleh Twitter API sebagai berikut.
a. Search API
b. Streaming API
c. REST API

\section{Metodologi}

\subsection{Metode Pengambilan Data}

Metode pengambilan data digunakan untuk mengumpulkan data- data pendukung yang dibutuhkan dalam proses pembuatan aplikasi. Beberapa cara yang dapat digunakan adalah melalui studi literatur, yaitu dengan mengumpulkan dan mempelajari beberapa referensi dari berbagai sumber yang berkaitan dengan judul penelitian yang dilakukan. Selain itu, untuk dataset yang digunakan diambil melalui Twitter API dengan proses crawling. Dataset yang diambil berupa file csv.

\subsection{Metode Pengolahan Data}

Data yang didapat dari Twitter API merupakan data yang langsung diambil dari tweet pengguna di Twitter. Data tersebut perlu dilakukan pengolahan agar menjadi data yang mudah digunakan dalam proses sentiment analysis. Tweet akan mengalami penyeleksian kata- kata sehingga tweet menjadi lebih ringkas. Beberapa komponen dari tweet akan dihapus untuk menyeleksi tweet. Proses ini dapat disebut dengan preprocessing. Setelah melalui preprocessing, data yang berupa teks akan diubah ke dalam bentuk angka melalui perhitungan $T F$ $I D F$. Nilai $T F \quad I D F$ ini yang akan menjadi masukan untuk algoritma Support Vector Machine. Algoritma Support Vector Machine akan menghasilkan klasifikasi untuk data yang dimasukkan.

\subsection{Metode Pengujian}

Pengujian yang dilakukan untuk menguji sistem dilakukan dengan 2 langkah pengujian, yaitu pengujian fungsionalitas dan pengujian akurasi sistem. Pengujian bertujuan untuk memastikan bahwa sistem yang dibangun telah berjalan sesuai dengan algoritma Support Vector Machine yang digunakan. 
a. Pengujian Fungsionalitas
b. Pengujian Akurasi Sistem

\section{Perancangan}

\subsection{Deskripsi Sistem}

Twitter Sentiment Analysis pada review film merupakan aplikasi berbasis website yang digunakan untuk klasifikasi sentiment berdasarkan dataset tweet yang diperoleh dari Twitter. Dataset yang digunakan memiliki 30 judul film dan maksimal 3.000 tweet berkaitan dengan review film. Algoritma yang akan digunakan merupakan salah satu algoritma Machine Learning, yaitu Support Vector Machine. Klasifikasi sentiment dibagi menjadi tiga, yaitu positif, negatif, dan netral. Hasil akhir dari aplikasi adalah klasifikasi sentiment berdasarkan kata kunci yang dimasukkan pengguna dan tingkat akurasi dari penggunaan algoritma Support Vector Machine dalam Twitter Sentiment Analysis.

\subsection{Analisis Sistem}

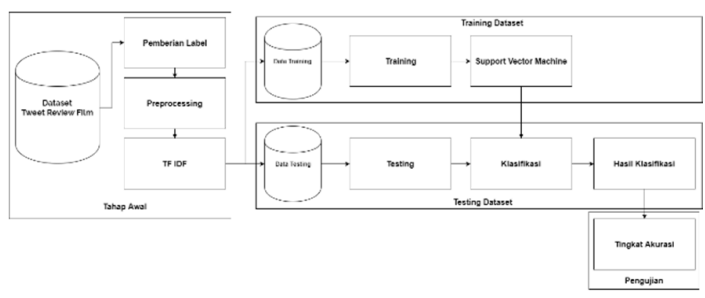

Gambar 3. Work Flow Sistem

Sistem yang akan dikembangkan akan dapat mengklasifikasikan tweet ke dalam positif, negatif, dan netral. Sistem tersebut merupakan satu kesatuan proses yang dapat menghasilkan hasil klasifikasi sesuai dengan data yang dimasukkan. Data yang digunakan diperoleh dari Twitter Search API. Sistem memiliki 4 sub proses yang menyusun sehingga dapat menghasilkan satu proses yang utuh. Sub proses yang terdapat dalam sistem sebagai berikut.

a. Tahap Awal

Tahap awal merupakan proses awal untuk mengolah dataset sebelum dapat digunakan untuk proses training dan testing. Data akan diambil dari Twitter Search API dengan menggunakan 30 kata kunci sesuai dengan 30 judul film yang sedang populer pada tahun 2016 .

Setelah pengambilan data, proses yang selanjutnya yaitu pemberian label atau klasifikasi secara manual. Tweet akan dibagi ke dalam positif, negatif, dan netral. Pemberian label dibantu oleh 3 orang. Pemberian label tersebut bertujuan untuk untuk memberikan klasifikasi secara manual terhadap tweet yang telah diperoleh. Label akan dihasilkan dari klasifikasi manual yang telah dilakukan tersebut. Pemberian label tersebut akan berguna untuk proses training dan testing.

Proses yang selanjutnya adalah preprocessing. Tahap ini memiliki manfaat untuk menghasilkan data masukan yang baik untuk proses training dan testing. Tahap preprocessing adalah tahap untuk menyeleksi kata- kata yang ada pada tweet sehingga menghasilkan kata- kata yang berisi sentimen dengan membuang kata- kata yang tidak diperlukan.

b. Training Dataset

Setelah preprocessing, tweet akan dihitung nilai $T F I D F$ yang dihasilkan. TF IDF merupakan proses untuk memecah tweet menjadi kata kata berdasarkan frekuensi kata yang digunakan dan nilai dari kata yang digunakan tersebut. Nilai dari setiap tweet akan menghasilkan nilai yang dapat digunakan untuk data masukan menuju ke proses training dan testing.

c. Testing Dataset

Proses testing adalah proses untuk menghasilkan klasifikasi tweet berdasarkan model classifier yang telah dihasilkan dari proses training dataset. Dataset yang digunakan sebagai data masukan berupa nilai $T F I D F$ yang telah dihitung pada tahap awal dan label yang dimiliki oleh tweet. TF IDF dan label akan membentuk koordinat, sehingga dapat dilihat batas- batas dari tweet dan membedakan antar tweet. Data yang digunakan untuk proses testing adalah 40, 30, 20, dan 10 persen dari jumlah keseluruhan dataset. Data akan diambil secara acak dari seluruh tweet yang ada. Hasil dari testing dataset adalah klasifikasi tweet ke dalam positif, negatif, atau netral.

d. Pengujian

Pengujian dari sistem yang dihasilkan dengan cara menghitung tingkat akurasi sistem. Tingkat akurasi didapatkan dengan membandingkan label dan hasil klasifikasi dari tweet pada proses testing dataset. Banyaknya kesamaan antara label dan klasifikasi akan meningkatkan tingkat akurasi dari sistem yang dihasilkan.

\section{Implementasi}

a. Database

Implementasi database dengan nama twitter_svm yang memiliki satu tabel, yaitu tabel datasets sesuai dengan analisis dan perancangan sebagai berikut. 


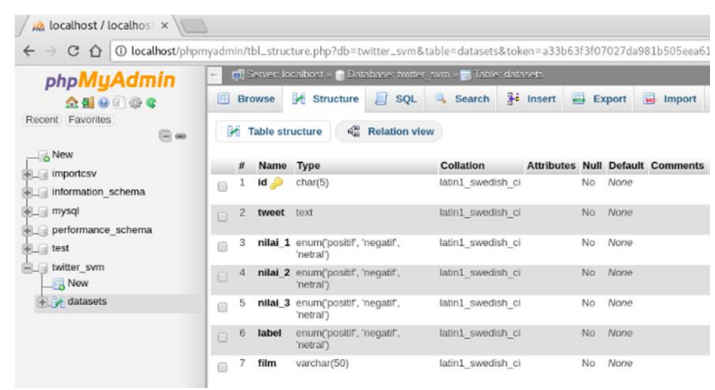

Gambar 4. Implementasi Database

b. Dataset

Interface menu dataset digunakan untuk menampilkan dataset yang akan digunakan dalam klasifikasi. Dataset telah melalui proses load dataset dari database sehingga data yang ditampilkan sama dengan data yang terdapat dalam database. Dataset terdiri dari enam kolom, yaitu tweet, nilai_1, nilai_2, nilai_3, label, dan film.

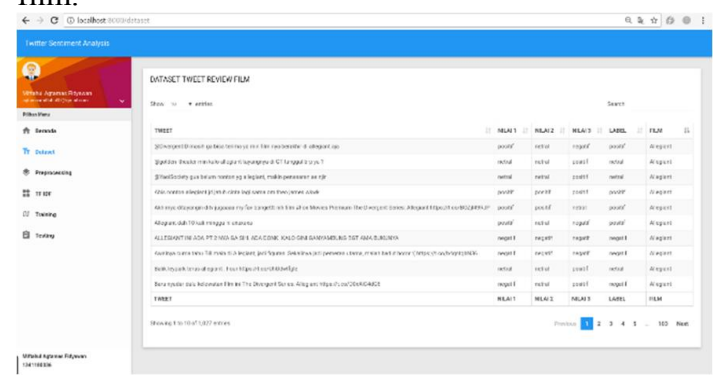

Gambar 5. Menu Dataset

c. Preprocessing

Interface menu preprocessing berisi informasi hasil dari tweet yang telah mengalami preprocessing sesuai dengan ketentuan preprocessing. Data ditampilkan dalam bentuk tabel yang terdiri dari tiga kolom, yaitu tweet, label, dan film.

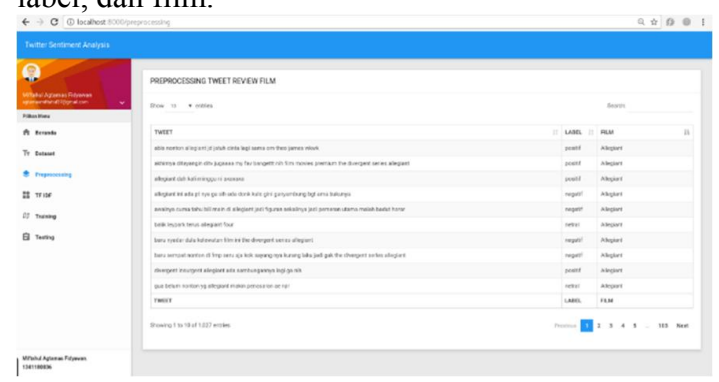

Gambar 6. Menu Preprocessing

d. $T F I D F$

Interface menu TF IDF berisi informasi tentang kata- kata yang telah dipecah dari tweet dan telah memiliki nilai $T F I D F$ sendiri.

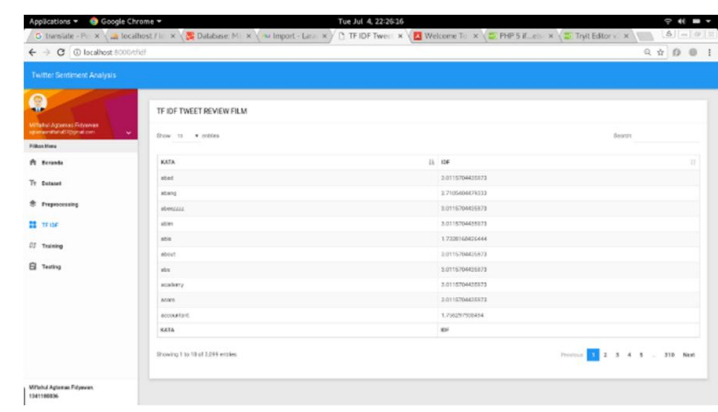

Gambar 7. Menu TF IDF

e. Training

Interface menu training berisi informasi dari dataset yang digunakan untuk proses training. Data ditampilkan dalam bentuk tabel dengan memiliki tiga kolom, yaitu tweet, label, dan film.

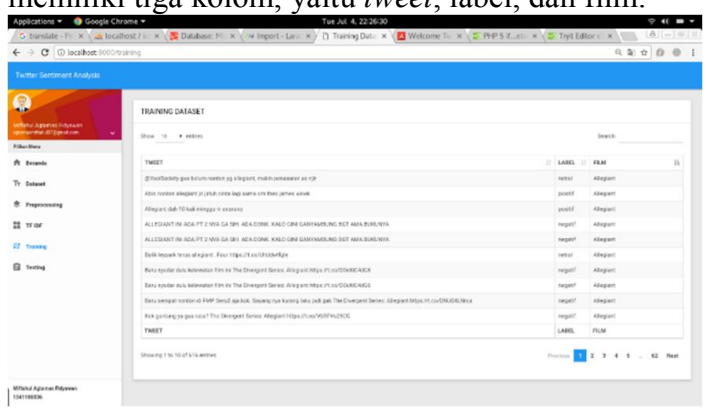

Gambar 8. Menu Training

\section{f. Testing}

Interface menu testing berisi informasi dari dataset yang digunakan untuk proses testing dan hasil dari klasifikasi. Interface menu testing juga menyediakan informasi tentang tingkat akurasi yang dihasilkan klasifikasi.

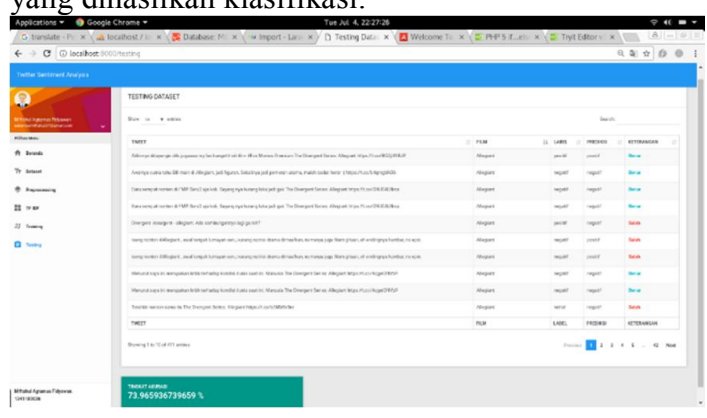

Gambar 9. Menu Testing

\section{Pengujian}

Uji coba dilakukan dengan uji coba fungsional terhadap layanan yang disediakan oleh sistem satu per satu dan uji coba terhadap tingkat akurasi klasifikasi yang dihasilkan oleh sistem. Uji coba fungsional terhadap layanan yang disediakan oleh sistem memiliki tujuan untuk mengetahui hasil dari setiap proses dalam klasifikasi telah sesuai dengan analisis dan perancangan yang dilakukan. Uji coba terhadap tingkat akurasi klasifikasi yang 
dihasilkan oleh sistem bertujuan untuk mengetahui nilai accuracy dan precision klasifikasi menggunakan algoritma SVM berdasarkan kesesuaian hasil klasifikasi dan label. a. Pengujian akurasi sistem

Pengujian akurasi sistem dilakukan dengan cara menghitung nilai dari accuracy dan precision. Rumus untuk menghitung nilai accuracy sebagai berikut.

$$
\frac{\sum v}{n} * 100
$$

Keterangan

$$
\begin{array}{ccc}
\mathrm{v} & \text { : } & \text { Jumlah data benar } \\
\mathrm{n} & : & \text { Jumlah dokumen }
\end{array}
$$

Sedangkan untuk menghitung nilai precision menggunakan rumus sebagai berikut.

$$
\frac{\sum v P}{n P} * 100
$$

$$
\begin{array}{ll}
\text { Keterangan } \\
\text { vP : } & \begin{array}{l}
\text { Jumlah data positif, negatif atau } \\
\\
\text { netral benar }
\end{array} \\
& \begin{array}{l}
\text { Jumlah dokumen positif, negatif } \\
\\
\quad \text { atau netral }
\end{array}
\end{array}
$$

Pengujian dilakukan dengan jumlah data training yang berbeda. Pada setiap data training akan dilakukan 5 kali pengujian, sehingga tingkat akurasi sistem akan dihitung berdasarkan ratarata dari setiap jumlah data training. Tabel 2 akan menyajikan hasil pengujian akurasi sistem.

Tabel 2.Pengujan Akurasi Sistem

\begin{tabular}{|c|c|c|c|c|}
\hline \multicolumn{5}{|c|}{ Data Training 60\% } \\
\hline P & Acc & Prec 1 & Prec -1 & Prec 0 \\
\hline $\mathbf{1}$ & 78,345 & 80,769 & 88,889 & 69,565 \\
\hline $\mathbf{2}$ & 76,886 & 80,321 & 93,103 & 66,917 \\
\hline $\mathbf{3}$ & 74,939 & 76,866 & 80 & 69,027 \\
\hline $\mathbf{4}$ & 76,156 & 82,895 & 66,667 & 68,056 \\
\hline $\mathbf{5}$ & 73,966 & 79,008 & 80 & 62,097 \\
\hline $\begin{array}{c}\text { Rata- } \\
\text { rata }\end{array}$ & $\mathbf{7 6 , 0 5 8 4}$ & $\mathbf{7 9 , 9 7 1 8}$ & $\mathbf{8 1 , 7 3 1 8}$ & $\mathbf{6 7 , 1 3 2 4}$ \\
\hline \multicolumn{5}{|c|}{ Data Training 70\% } \\
\hline P & Acc & Prec 1 & Prec -1 & Prec 0 \\
\hline $\mathbf{1}$ & 76,699 & 78,680 & 88,235 & 66,667 \\
\hline $\mathbf{2}$ & 75,081 & 77,005 & 86,207 & 67,742 \\
\hline $\mathbf{3}$ & 77,346 & 79,545 & 96,667 & 67,961 \\
\hline $\mathbf{4}$ & 76,700 & 80,978 & 79,107 & 68,317 \\
\hline $\mathbf{5}$ & 78,317 & 77,348 & 86,842 & 76,667 \\
\hline $\begin{array}{c}\text { Rata- } \\
\text { rata }\end{array}$ & $\mathbf{7 6 , 8 2 8 6}$ & $\mathbf{7 8 , 7 1 1 2}$ & $\mathbf{8 7 , 4 1 1 6}$ & $\mathbf{6 9 , 4 7 0 8}$ \\
\hline \multicolumn{5}{|c|}{ Data Training 80\% } \\
\hline P & Acc & Prec 1 & Prec-1 & Prec 0 \\
\hline
\end{tabular}

\begin{tabular}{|c|c|c|c|c|}
\hline \multicolumn{5}{|c|}{ Data Training 60\% } \\
\hline P & Acc & Prec 1 & Prec -1 & Prec 0 \\
\hline 1 & 82,524 & 89,744 & 83,333 & 70,423 \\
\hline 2 & 83,010 & 88,095 & 85,714 & 71,186 \\
\hline 3 & 81,068 & 83,594 & 78,947 & 76,271 \\
\hline 4 & 82,039 & 80 & 100 & 82,813 \\
\hline 5 & 76,700 & 78,689 & 88,889 & 69,697 \\
\hline $\begin{array}{c}\text { Rata- } \\
\text { rata }\end{array}$ & $\mathbf{8 1 , 0 6 8 2}$ & $\mathbf{8 4 , 0 2 4 4}$ & $\mathbf{8 7 , 3 7 6 6}$ & $\mathbf{7 4 , 0 7 8}$ \\
\hline \multicolumn{5}{|c|}{ Data Training 90\% } \\
\hline P & Acc & Prec 1 & Prec -1 & Prec 0 \\
\hline $\mathbf{1}$ & 81,553 & 82,813 & 100 & 72,414 \\
\hline $\mathbf{2}$ & 86,408 & 86,885 & 91,667 & 83,333 \\
\hline $\mathbf{3}$ & 78,641 & 81,429 & 88,889 & 66,667 \\
\hline $\mathbf{4}$ & 89,320 & 93,750 & 87,500 & 78,261 \\
\hline $\mathbf{5}$ & 80,583 & 82,813 & 100 & 70 \\
\hline $\begin{array}{c}\text { Rata- } \\
\text { rata }\end{array}$ & $\mathbf{8 3 , 3 0 1}$ & $\mathbf{8 5 , 5 3 8}$ & $\mathbf{9 3 , 6 1 1 2}$ & $\mathbf{7 4 , 1 3 5}$ \\
\hline
\end{tabular}

Keterangan :

$$
\begin{array}{lll}
\text { P } & : & \text { Pengujian ke- } \\
\text { Acc } & : & \text { Accuracy } \\
\text { Prec 1 } & : & \text { Precision } \text { Positif } \\
\text { Prec }-1 & : & \text { Precision Negatif } \\
\text { Prec 0 } & : & \text { Precision Netral }
\end{array}
$$

Berdasarkan Tabel 2, terdapat perbedaan nilai accuracy dan nilai precision dari beberapa pengujian dengan jumlah data training yang berbeda. Hal tersebut menunjukkan bahwa semakin besar data training yang digunakan, maka nilai accuracy dan nilai precision cenderung mengalami peningkatan.

\section{Kesimpulan}

Berdasarkan hasil penelitian dan pengujian yang telah dilakukan dapat ditarik kesimpulan sebagai berikut :

a. Algoritma Support Vector Machine dapat digunakan untuk klasifikasi tweet tentang review film.

b. Pengujian dengan menggunakan jumlah data training yang berbeda menghasilkan semakin banyak data training yang digunakan, nilai accuracy dan nilai precision yang cenderung mengalami peningkatan.

\section{Daftar Pustaka:}

Akshay Amolik, et al., (2016), “Twitter Sentiment Analysis of Movie Reviews using Machine Learning Techniques", International Journal of Engineering and Technology" (IJET). vol 7. no 6, p-ISSN.2319-8613.

S. Sahu, et al., (2015), "Twitter Sentiment Analysis, A More Enhanced Way of Classification and Scoring". 2015 IEEE International Symposium on Nanoelectronic and Information Systems.

O. Abdelwahab, (2016), "Effect of Training Size on SVM and Naive Bayes for Twitter Sentiment 
Analysis", IEEE International Symposium on Signal Processing and Information Technology (ISSPIT).

Feldman, R, Sanger, J, (2007), “The Text Mining Handbook: Advanced Approaches in Analyzing Unstructured Data". New York: Cambridge University Press.

Berry, M.W., Kogan, J, (2010) "Text Mining Aplication and Theory". United Kingdom: Wiley.

Pang, Bo and Lee, L, Vaithyanathan, S, (2002), "Sentiment Classification Using Machine Learning Techniques". Proceedings of the 7th Conference on Empirical Methods in Natural Language Processing" (EMNLP-02). USA.

E. Boiy, et al., (2007) "Automatic Sentiment Analysis in on-line Text", Proceedings ELPUB2007 Conference on Electronic Publishing. 
Volume 4, Edisi 2, Februari 2018

H a 1 a $m$ a $n \mid \mathbf{1 0 0}$ 